\title{
Grid Impedance Estimation for Single Phase PV Grid Tide Inverter Based on Statistical Signal Processing Techniques
}

\author{
$1^{\text {st }}$ Hamza Khalfalla \\ School of Engieering, Newcastel \\ University \\ Newcastel Upon Tyne, UK \\ Hamza.khalfalla@ncl.ac.uk
}

\author{
${ }^{1}$ Salaheddine Ethni \\ School of Engieering, Newcastel \\ University \\ Newcastel Upon Tyne, UK \\ Salaheddine.ethni@ncl.ac.uk
}

\author{
${ }^{1}$ M. Shiref \\ School of Engieering, Newcastel \\ University \\ Newcastel Upon Tyne, UK \\ muez.shiref@ncl.ac.uk
}

\author{
${ }^{2}$ Maher Al-Greer \\ School of Science, Engineering \\ and Design, Teesside University \\ Middlesbrough, Tees Valley, UK \\ m.al-greer@tees.ac.uk
}

\author{
${ }^{1}$ Volker Pickert \\ School of Engieering, Newcastel \\ University \\ Newcastel Upon Tyne, UK \\ Volker.pickert@ncl.ac.uk
}

\author{
${ }^{1}$ Matthew Armstrong \\ School of Engieering, Newcastel \\ University \\ Newcastel Upon Tyne, UK \\ matthew.armstrong@ncl.ac.uk
}

\begin{abstract}
This paper presents an effective approach to detect the variation of the grid impedance for single phase PV grid connected inverter interfaced by LCL filter. The proposed technique entails the use of a digital Sallen-Key band pass filter placed at the point of common coupling (PCC) to filter out the harmonic components around the resonance frequency. Series of statistical signal processing steps are applied to the output signal of the band pass filter in order to identify the grid impedance variation. The techniques described in this paper can be deployed to tune the current controller gains using gain-scheduling method; it can also be utilized in islanding detection leading to power quality enhancement. MATLAB/Simulation results based on experimental data of $\mathrm{PV}$ grid inverter system subjected to wide range of impedance variation are presented to validate the proposed method.
\end{abstract}

Keywords-LCL Filter, Bandpass filter, Resonance Detection, Grid Impedance Estimation.

\section{INTRODUCTION}

The penetration of Photovoltaic systems (PV) connected to grid are increasing rapidly to reach a total installed capacity of approximately $294 \mathrm{GW}$ in 2016 [1]. In particular they are gaining fame and popularity due to their suitability for both, standalone systems such as houses and institutions and grid connected systems [2, 3]. Due to the time varying of grid operation condition, smart interface between dispatchers and the network that employs such distribution generation systems (DPGS) might be essential in order to satisfy the consumer's demands in one hand and, for safety and reliability purposes on the other hand [4]. The reason behind grid system impedance variation is a combination between several factors including transformers, cables, and loads. Apart from medium and high voltage transformers impedance (mainly inductive), the low voltage cables introduce a prevalently resistive impedance that changes according to the distance between the PV system and the transformer [5]. Indeed, the grid impedance information is of prime importance for inverter filter design, grid failure detection, compliance with standard specification such as IEEE929, IEEE1547 and VDE0126, islanding operation and last but not least, control loop tuning [4]. In general, the state of art classifies the grid impedance prediction and estimation techniques into two main categories $[6,7]$ :

Invasive method where one or more disturbances harmonic signals injected to the system in randomly or periodically way. These disturbances can be at low frequency rage as reported in $[8,9]$, or high frequency range as presented in [10], to excite the system response. Based on system response, the grid impedance can be estimated from the current and voltage measurements.

In contrast, non-invasive method which depends on the measured excitation of the natural load variation to determine the impedance value as presented in [11, 12]. Both categories has its own drawbacks which make it difficult to be implemented in undedicated platform (i.e. PV inverter systems).

For on-line estimation of the grid impedance, the work in [13] presented a classical Kalman filter based on the inherent disturbances at point of common coupling (PCC) and by utilizing an observer-based parameters identification. However, this method suffers from complicated tuning processing. Alternative technique was proposed in [14], by producing a small perturbation in the form of periodical active and reactive power variation. More associated researches can be found in [15-18].

In modern manufacturing inverter application, low pass LCL filter is preferable to interface the grid for smoothing current injection. This is mainly because of their advantages over $\mathrm{L}$ and 
LC filters in terms of harmonic attenuation, overall weight and size reduction and cost saving [19]. However, undesired resonant effect of LCL filter might be raised and lead to instability [20]. For this reason, this paper proposes a new method to track the variation in the grid impedance by utilizing the oscillated resonant frequency. To achieve this, a digital Sallen-Key band pass filter is designed to filter out the harmonic components around the resonance frequency of PCC voltage waveform.The output signal from the band pass filter is statistically processed to detect the impedance variations. It worth to point out that only the inductive part is considered, as increasing in grid inductance leads to unstable distribution system [7]. The paper is organized as follow: Section II presents the system description along with the proposed method including the effect of grid impedance variation on the resonance of LCL filter. Measured results are presented in Section III. Finally, conclusions from this work are presented in sections IV.

\section{PROPOSED METHOD}

\section{A. System Discribtion}

Fig. 1 shows the schematic diagram of single phase $\mathrm{H}$ - bridge inverter interfacing the grid by Line LCL filter in series with emulated grid tapped inductor. Importantly, it shows the position of voltage sensor at the point of common coupling PCC and the position of the grid side current sensor at the grid side. The signal of PCC voltage is fed to a digital band pass filter, then the output ending up to a digital signal processing in the control platform. Phase locked loop PLL block is implemented for ensuring unity power factor and synchronization purposes.

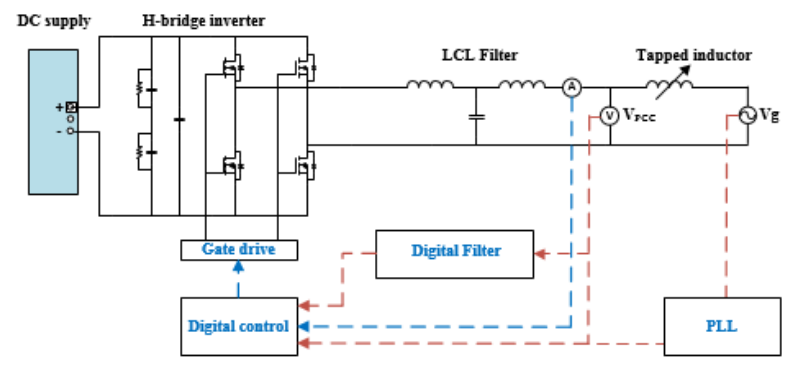

Fig.1. Schemetic diagrim of simulated grid inverter system.

\section{B. Effect of grid inductance on LCL filter resonance}

The system shown in Fig.1, has been investigated under wide range of grid inductance by varying the emulated tapped inductance. According to IEC60725 standards [21], the UK residential consumers complex supply impedance for single phase connection at $50 \mathrm{~Hz}$ can varies up to approximately 0.8 $\mathrm{mH}$ for the worst case scenario (weak grid) and down to a neglected inductance (stiff grid). It has been shown that (see Fig.2) once the inverter system is connected to the main, the LCL resonant frequency given in equation (1) is highly depends on the grid inductor.

$$
\sqrt{\frac{L 1+L 2+L g}{L 1 \times(L 2+L g) \times C f}}
$$

Where, $L_{1}, L_{2}, L_{g}$ and $C_{f}$ are: inverter side inductor, grid side inductor, grid impedance inductor and filter capacitor respectively.

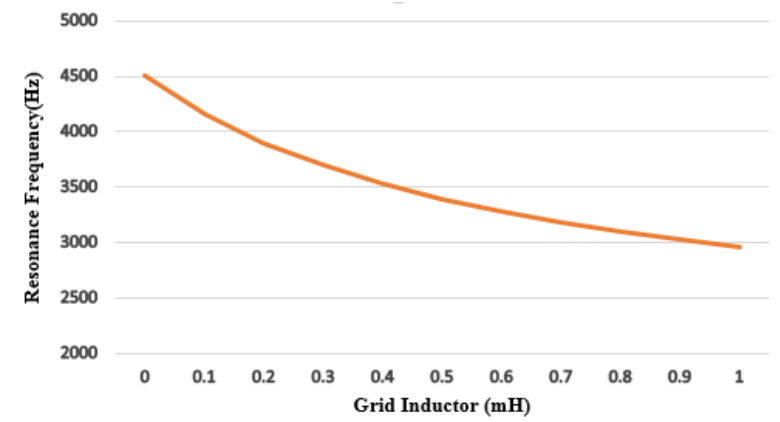

Fig. 2. Resonance frequency variation as function of grid inductance.

As shown in Fig.2, the resonant frequency can experience a drop up to $30 \%$ in the case of weak grid due to the increase of grid inductance. In this case the dynamic and stability problems might rise in the low frequency range around the bandwidth of the controller frequency. On the contrary, these problems are also applicable in the high frequency range around LCL filter resonant frequency. The relationship between the system resonance frequency and system stability has been analysed and detailed in [22].

\section{Design and digital implementation of bandpass filter}

Fig. 3 shows a second order Sallen-key bandpass filter. The fourth order filter can be shaped by cascading two second order filters. In this work, the designed forth order bandpass filter operates between $3 \mathrm{kHz}$-to- $4.5 \mathrm{kHz}$, which is the bandwidth of harmonic components around the resonant frequency. It is important to mention that the bandwidth of the filter has been selected based on FFT analysis for the PCC voltage waveform, and calculation of the resonant frequency given in equation 1 . The specification of the forth order bandpass filter is given in table 1 .

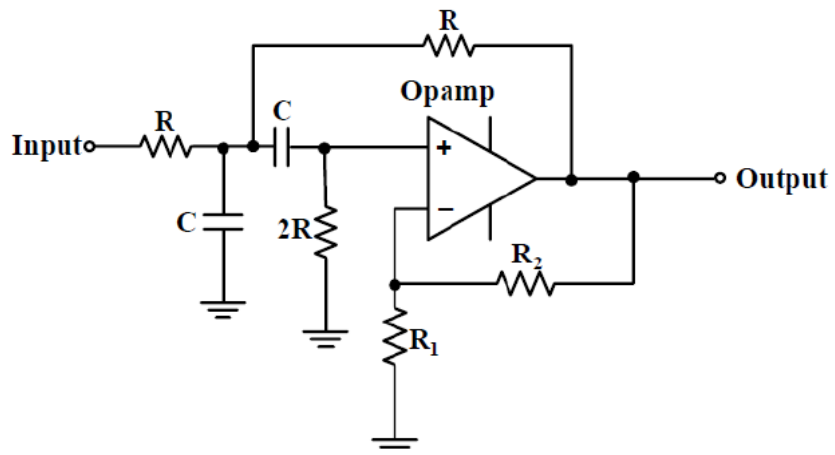

Fig.3. Schemetic diagrim of second orther analoug bandpass filter.. 
TABLE.I SPECIFICATION OF BANDPASS FILTER

\begin{tabular}{|c|c|c|c|c|}
\hline Topology & order & response & $\begin{array}{c}\text { Central } \\
\text { frequency }\end{array}$ & bandwidth \\
\hline Sallen-Key & 4 th & Butterworth & $3750 \mathrm{~Hz}$ & $1500 \mathrm{~Hz}$ \\
\hline
\end{tabular}

For the digital implementation of the bandpass filter, the discretization method has to be carefully selected, because many of the existing techniques can result in poles displacement and frequency deviation respect to the continuous transfer function [23]. This can be achieved using the "c2z" function in Matlab with a suitable discretization method. Zero order hold $(\mathrm{ZOH})$ has been selected due to its ability to produce identical match in the frequency domain between the continuous and discrete transfer function. The $s$-domain transfer function of the bandpass filter is given in equation (2) and the Corresponding $z$ domain transfer function is given in equation (3).

$$
\begin{aligned}
& B P(s)=\frac{4.09 e^{9} 5 s^{2}}{s^{4}+1.332 e^{4} s^{3}+1.155 e^{9} s^{2}+7.388 e^{12} s+3.076 e^{17}} \\
& B P(z)=\frac{3.206 z^{3}-3.826 z^{2}-1.978 z+2.598}{z^{4}-1.333 z^{3}+1.874 z^{2}-0.9546 z+0.5137}
\end{aligned}
$$

As illustrated in Fig.4, the frequency response characteristic for both $s$-domain and $z$-domain are obviously identical. The filter high gain (38) will magnify the magnitudes of the harmonic components around the resonant frequency where the harmonic components around the fundamental frequency are attenuated to $-56 \mathrm{~dB}$.

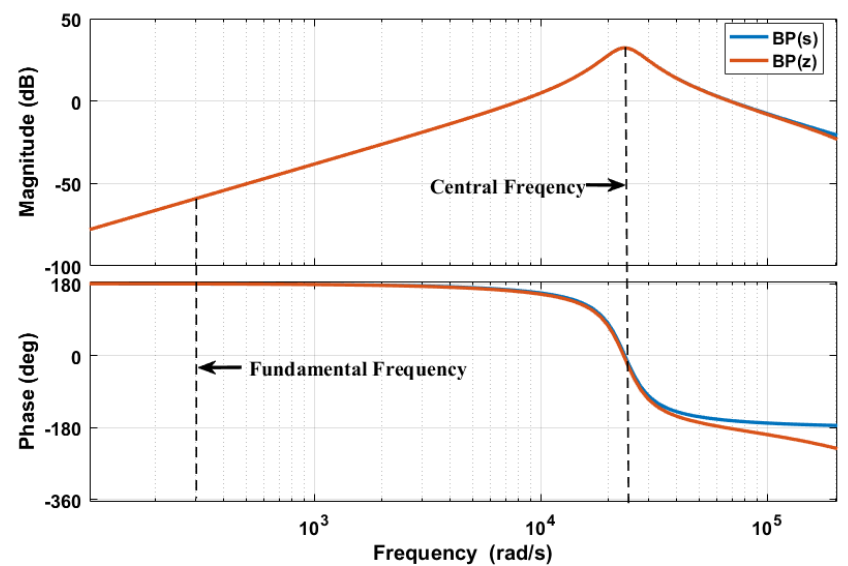

Fig. 4. Frequency response comparison between $s$ - domain and $z$-domain transfer function

The next step following the bandpass filtering is statistical signal processing chain which consist of the following analysis: rectifying, integrating and averaging of the obtained signal (Fig.5). The resulted average value is found to be different for every inductance of the emulated grid impedance inductor.
These values can be readable by microprocessor and considered for further action such as control adaptation and islanding detection.

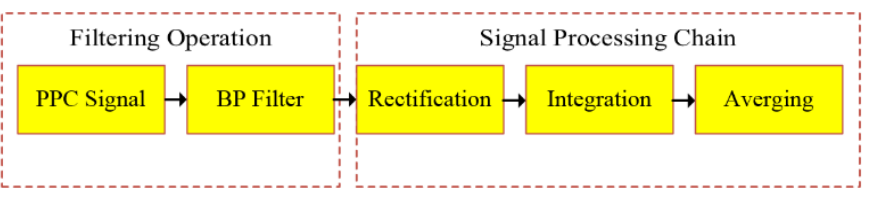

Fig.5. Signal processing chain .

\section{RESULTS}

The single phase grid connected PV inverter depicted earlier in Fig. 1 has been modelled in MATLAB/Simulink. The grid voltage block has been created based on experimental date of the utility network that available for the research group in electrical power laboratory at Newcastle University. The model consists of different magnitudes and phase angles summed together to form a grid voltage signal with $2.47 \%$ total harmonic distortion (THD) as shown in Fig. (6).

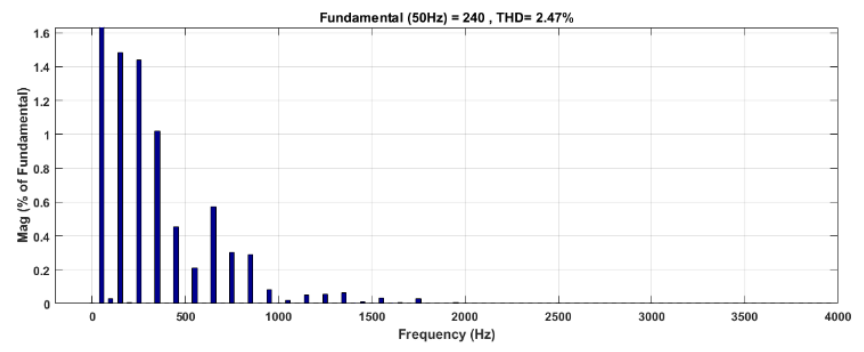

Fig. 6. THD \% of harmonic poluted grid voltag .

As the PCC voltage signal (see Fig7 (a) and 8 (a)) goes throw the digital bandpass filter, the filter high pass gain will allow only the harmonic component around the resonant frequency to be passed in the form of an oscillated signal, while attenuating those components around the fundamental frequency. This can be easily spot on Fig. 4, where the attenuation gain is equal to $-56 \mathrm{~dB}$ as illustrated in Fig (4).

Fig.7 and Fig.8 shows the simulation results of the system being connected to a grid impedance of $0.1 \mathrm{mH}$ and $0.8 \mathrm{mH}$ respectively. As can be seen from Fig.7 (b), the asymmetrical oscillation of the filtered signal in the case of $\mathrm{Lg}=0.1 \mathrm{mH}$ is less than that of $\mathrm{Lg}=0.8 \mathrm{mH}$ which presented in Fig. 8 (b). In fact, it has been found that the higher the grid inductor the more oscillation presents in the voltage signal. The next step in processing chain is rectifying the filtered signal to offset the negative part yields, the rectifying signals shown in Fig.7 (c) and 8 (c) for $\mathrm{Lg}=0.1 \mathrm{mH}$ and $\mathrm{Lg}=0.8 \mathrm{mH}$ respectively.

The results shown in Fig.7 (d) and Fig.8 (d) show the second step which is the integration output of the rectified signal. Again, the change in the grid inductance can be linked to the change of resonant frequency, where the peak points of the integrated signal related to $\mathrm{Lg}=0.8 \mathrm{mH}$ is significantly bigger than those of $\mathrm{Lg}=0.1 \mathrm{mH}$. The last step in the signal processing is the averaging which is done by taking the average of the last ten 
cycles of the integrating signal (see Table II). The resulted value in every case is the corresponding value of the grid impedance.

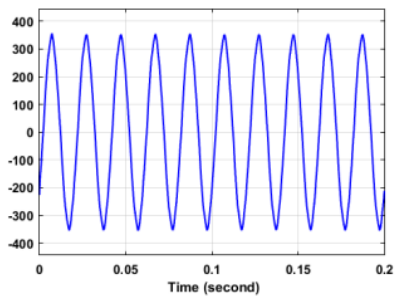

(a)

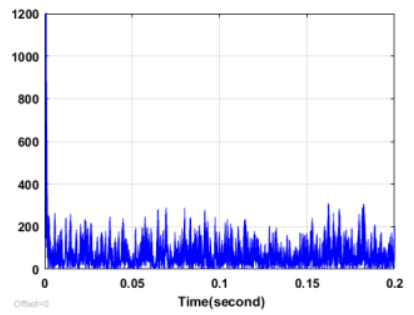

(c)

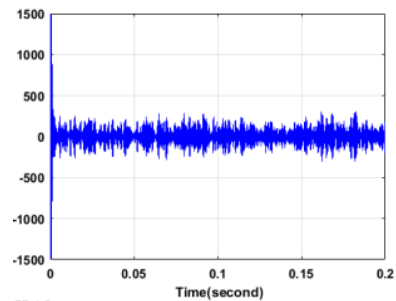

(b)

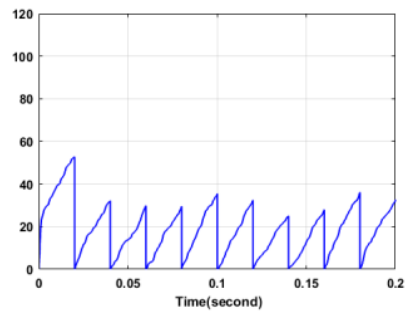

(d)
Fig.7 Simulation results of filtering and signal processing chain of $\operatorname{Lg}=0.1$ $\mathrm{mH}$ : (a) Filter input Vpcc signal. (b) Filter output signal, (c) Rectifying signal, and (d) integrated signal.

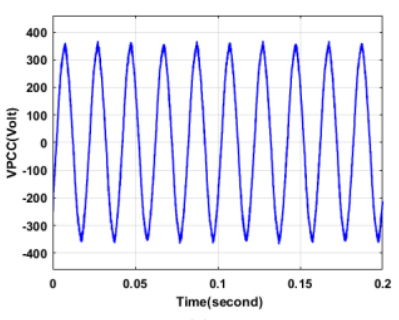

(a)

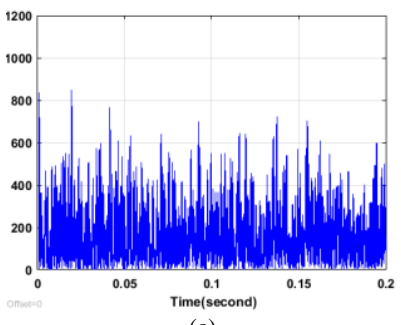

(c)

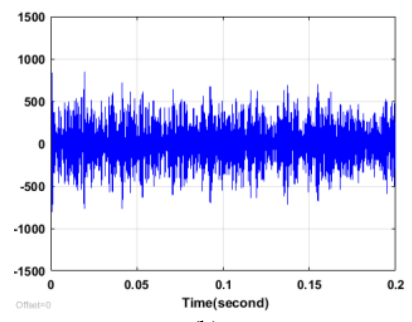

(b)

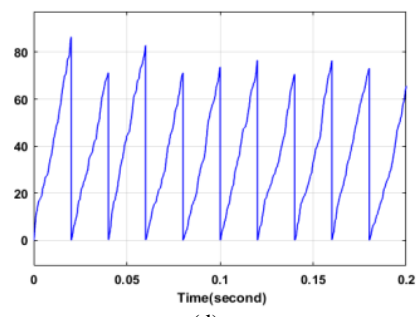

(d)
Fig.8 Simulation results of filtering and signal processing chain of $\mathrm{Lg}=0.8$ mH: (a) Filter input Vpcc signal. (b) Filter output signal, (c) Rectifying signal, and (d) integrated signal.

\begin{tabular}{|c|c|c|c|c|c|c|c|c|c|c|c|}
\hline \multirow{2}{*}{$\begin{array}{c}\mathrm{Lg} \\
(\mathrm{mH})\end{array}$} & \multicolumn{10}{|c|}{ Maximum values of the last ten cycle } & \multirow{2}{*}{$\begin{array}{l}\text { Average } \\
\text { value }\end{array}$} \\
\hline & 1 & 2 & 3 & 4 & 5 & 6 & 7 & 8 & 9 & 10 & \\
\hline 0.1 & 52.74 & 32.16 & 29.85 & 29.99 & 31.87 & 35.43 & 25.01 & 35.75 & 32.21 & 27.98 & 30.50 \\
\hline 0.8 & 86.47 & 71.22 & 82.87 & 71.19 & 73.4 & 70.6 & 76.57 & 75.88 & 73.11 & 65.17 & 74.84 \\
\hline
\end{tabular}

\section{CONCLUSION}

Based on the fact that online identification of grid impedance is essential for stability and reliability of grid tide inverter, this paper has proposed a grid impedance estimation method that can be utilized for adaptive regulators and islanding detection. The method implements a high order digital bandpass filter and chain of statistic signal processing for resonance detection and analysis. It has been found the changeable grid impedance can be tracked and estimated according to the system resonance variation. Comparing with other methods, this technique can be promised in term of simplicity and cost effectiveness hence, no additional hardware is needed as all the captured data are collected from the already installed devices and sensors of the system.

\section{REFERENCES}

J. Liu, L. Zhou, B. Li, C. Zheng, and B. Xie, "Modeling and Analysis of a Digitally Controlled Grid-Connected LargeScale Centralized PV System," IEEE Transactions on Power Electronics, vol. 33, pp. 4000-4014, 2018.

C. Citro, P. Siano, and C. Cecati, "Designing Inverters 2019; Current Controllers With Resonance Frequencies Cancellation," IEEE Transactions on Industrial Electronics, vol. 63, pp. 3072-3080, 2016.

N. Agarwal, M. W. Ahmad, and S. Anand, "Quasi-Online Technique for Health Monitoring of Capacitor in SinglePhase Solar Inverter," IEEE Transactions on Power Electronics, vol. 33, pp. 5283-5291, 2018.

M. J. B. Ghorbal, W. Ghzaiel, I. Slama-Belkhodja, and J. M. Guerrero, "Online detection and estimation of grid impedance variation for Distributed Power Generation," in 2012 16th IEEE Mediterranean Electrotechnical Conference, 2012, pp. 555-560.

M. Liserre, R. Teodorescu, and F. Blaabjerg, "Stability of grid-connected PV inverters with large grid impedance variation," in 2004 IEEE 35th Annual Power Electronics Specialists Conference (IEEE Cat. No.04CH37551), 2004, pp. 4773-4779 Vol.6.

A. Ghanem, M. Rashed, M. Sumner, M. A. Elsayes, and I. I. I. Mansy, "Grid impedance estimation for islanding detection and adaptive control of converters," IET Power Electronics, vol. 10, pp. 1279-1288, 2017.

M. A. Azzouz and E. F. El-Saadany, "Multivariable Grid Admittance Identification for Impedance Stabilization of Active Distribution Networks," IEEE Transactions on Smart Grid, vol. 8, pp. 1116-1128, 2017.

L. Asiminoaei, R. Teodorescu, F. Blaabjerg, and U. Borup, "A digital controlled PV-inverter with grid impedance estimation for ENS detection," IEEE Transactions on Power Electronics, vol. 20, pp. 1480-1490, 2005.

L. Asiminoaei, R. Teodorescu, F. Blaabjerg, and U. Borup, "Implementation and Test of an Online Embedded Grid Impedance Estimation Technique for PV Inverters," IEEE Transactions on Industrial Electronics, vol. 52, pp. 11361144, 2005.

Z. Staroszczyk, "A method for real-time, wide-band identification of the source impedance in power systems," IEEE Transactions on Instrumentation and Measurement, vol. 54, pp. 377-385, 2005.

J. Sun, "Impedance-Based Stability Criterion for GridConnected Inverters," IEEE Transactions on Power Electronics, vol. 26, pp. 3075-3078, 2011. 
[12] G. Herong, X. Guo, W. Deyu, and W. Wu, "Real-time grid impedance estimation technique for grid-connected power converters," in 2012 IEEE International Symposium on Industrial Electronics, 2012, pp. 1621-1626.

[13] N. Hoffmann and F. W. Fuchs, "Minimal Invasive Equivalent Grid Impedance Estimation in Inductive Resistive Power Networks Using Extended Kalman Filter," IEEE Transactions on Power Electronics, vol. 29, pp. 631641, 2014.

[14] M. Ciobotaru, R. Teodorescu, P. Rodriguez, A. Timbus, and F. Blaabjerg, "Online grid impedance estimation for singlephase grid-connected systems using PQ variations," in 2007 IEEE Power Electronics Specialists Conference, 2007, pp. 2306-2312.

[15] S. Cobreces, E. J. Bueno, D. Pizarro, F. J. Rodriguez, and F. Huerta, "Grid Impedance Monitoring System for Distributed Power Generation Electronic Interfaces," IEEE Transactions on Instrumentation and Measurement, vol. 58, pp. 3112-3121, 2009.

[16] J. Yang, W. Li, T. Chen, W. Xu, and M. Wu, "Online estimation and application of power grid impedance matrices based on synchronised phasor measurements," IET Generation, Transmission \& Distribution, vol. 4, pp. 10521059, 2010.

[17] V. Valdivia, A. Lazaro, A. Barrado, P. Zumel, C. Fernandez, and M. Sanz, "Black-Box Modeling of Three-Phase Voltage Source Inverters for System-Level Analysis," IEEE Transactions on Industrial Electronics, vol. 59, pp. 3648$3662,2012$.
[18] D. Martin and E. Santi, "Autotuning of Digital Deadbeat Current Controllers for Grid-Tie Inverters Using Wide Bandwidth Impedance Identification," IEEE Transactions on Industry Applications, vol. 50, pp. 441-451, 2014.

[19] A. Reznik, M. G. Simões, A. Al-Durra, and S. M. Muyeen, Filter Design and Performance Analysis for GridInterconnected Systems," IEEE Transactions on Industry Applications, vol. 50, pp. 1225-1232, 2014.

[20] C. Zou, B. Liu, S. Duan, and R. Li, "Influence of Delay on System Stability and Delay Optimization of Grid-Connected Inverters With LCL Filter," IEEE Transactions on Industrial Informatics, vol. 10, pp. 1775-1784, 2014.

[21] I. Hernando-Gil, H. Shi, F. Li, S. Djokic, and M. Lehtonen, "Evaluation of Fault Levels and Power Supply Network Impedances in 230/400 V $50 \mathrm{~Hz}$ Generic Distribution Systems," IEEE Transactions on Power Delivery, vol. 32, pp. 768-777, 2017.

[22] B. Xie, L. Zhou, C. Zheng, and Q. Zhang, "Stability and resonance analysis and improved design of $\mathrm{N}$-paralleled grid-connected PV inverters coupled due to grid impedance," in 2018 IEEE Applied Power Electronics Conference and Exposition (APEC), 2018, pp. 362-367.

[23] A. G. Yepes, F. D. Freijedo, J. Doval-Gandoy, L. Ó, J. Malvar, and P. Fernandez-Comesaña, "Effects of Discretization Methods on the Performance of Resonant Controllers," IEEE Transactions on Power Electronics, vol. 25, pp. 1692-1712, 2010.

School of Engineering, Newcastle University. 